\title{
La aceleración social como nueva frontera para la ética del turismo
}

\author{
Social Acceleration as a New Frontier for the Ethics \\ of Tourism
}

JOSÉ L. LÓPEZ-GONZÁLEZ1 (Universitat Jaume I) y DAVID A. FENNELL (Brock University)

López-González, José L. y Fennell, David A. (2021). La aceleración social como nueva frontera para la ética del turismo. Recerca. Revista de Pensament i Análisi, 26(1), pp. 1-8. doi: http://dx.doi.org/10.6035/Recerca.2021.26.1.1

La ética del turismo ha ido adquiriendo una gran relevancia en los debates sobre la deslegitimación del turismo. Y, ante las valoraciones sobre «cómo debería ser» el turismo que parecen subyacer a muchos de estos debates (Caton, 2012), su paulatina sistematización como disciplina ha ido poniendo de manifiesto finalmente dos aspectos. Por un lado, la necesidad de extender el análisis de los impactos del turismo a sus causas subyacentes, con el fin de contar con diagnósticos desde los que reconstruir los horizontes de legitimación del turismo. Y, por otro lado, superar las concepciones tradicionales y estáticas del turismo, porque, a diferencia de muchas actividades, es extraordinariamente heterogéneo, escurridizo y difícilmente controlable (Fennell, 2018).

En este contexto, uno de los retos que se le presenta a la ética del turismo es cómo dar cuenta de las recurrentes referencias - entre muchas otras-a la velocidad, al cambio continuo o al crecimiento que están insertadas no solo en nuestro lenguaje cotidiano, sino en los estudios turísticos. Por ejemplo, una de las cuestiones más preocupantes tiene que ver con el impacto ecológico que arrastra el turismo durante las últimas décadas (Fennell, 1999). Aunque suspendidas momentáneamente por la crisis mundial generada por la COVID, las implicaciones medioambientales asociadas a la dinámica de crecimiento constituyen una cuestión ineludible para el futuro del turismo (Gössling, Scott y

Esta publicación se enmarca en el Proyecto de Investigación Científica y Desarrollo Tecnológico «Ética aplicada y confiabilidad para una Inteligencia Artificial» PID2019-109078RB-C21, financiado por el Ministerio de Ciencia, Innovación y Universidades. 
Hall, 2020). Incluso permiten plantear si acaso no sería necesario desarrollar un ethos ecológico que opte por la autolimitación (Conill-Sancho, 2019). Otras cuestiones, como las consecuencias para el desarrollo de los proyectos de vida que supone el incremento de tareas en los trabajos turísticos (López-González y Medina-Vicent, 2020) o el uso de neurotecnologías en el turismo - conocidas como neuroturismo- con el fin de aumentar la productividad sectorial a costa de una reducción al máximo del tiempo de interacción con el potencial turista (López-González, 2019), son solo algunos ejemplos de los muchos trabajos formulados por el amplio abanico de disciplinas de los estudios turísticos que revelan las dificultades para sustraerse de la utilización de toda una variedad de conceptos que, de un modo u otro, también acaban haciendo referencia al carácter desbocado del turismo (Tribe, 2009).

Para abordar estas referencias, algunos colectivos han propuesto una perspectiva ética bajo el marco rápido-lento (Fullagar, Markwell y Wilson, 2012; Clancy, 2018). No obstante, ¿es suficiente una aproximación dicotómica? ¿Hay algo en común en toda esa amalgama de referencias? La magnitud del turismo y las dimensiones que este abarca no permiten responder fácilmente a esta pregunta. Pero es tarea de la ética contar con las voces de los afectados y de las disciplinas que puedan dar cuenta de las actividades sociales (Cortina, 2003). Y, para ello, ha de ser capaz de incluir nuevos vocabularios para comprender qué dimensión ética subyace a las expectativas puestas en cada una de ellas (García-Marzá, 2003).

En este sentido, este monográfico propone la utilización de una perspectiva analítica como es la de la aceleración (Harvey, 1989; Rosa, 2005) como punto de partida para una articulación entre la crítica y la ética del turismo. Los siguientes textos reflejan diferentes modos de entender este vínculo.

El trabajo de Tazim Jamal y Jaume Guia se centra en uno de los retos a los que ha conllevado la aceleración social: la coordinación y la regulación global del turismo. Este constituye, por sí mismo, una actividad de extrema complejidad y difícil delimitación. Pero el incremento de la movilidad física y virtual a nivel global en unas condiciones productivistas y de desregulación ha puesto de manifiesto sus dificultades para desarrollarse de un modo justo y sostenible. En este contexto, los retos del turismo no pueden ser delegados solo en las organizaciones supranacionales. Además de contener limitaciones prácticas a la hora de actuar, su orientación hacia la defensa de unos intereses generalizables se encuentra en entredicho (López-González, 2018a; Fennell, 2019). La propuesta de los autores se centra en fundamentar el potencial de alternativas más allá de las organizaciones supranacionales. Mediante una radicalización 
del cosmopolitismo kantiano a través de Gilles Deleuze, los autores proponen que, si lo que se desea es avanzar hacia un horizonte de transformación radical hacia la justicia en y a través del turismo, este camino no puede apoyarse solo en una fundamentación trascendental de la moral. La pedagogía y la praxis turística se presentan como dos campos que pueden contribuir a la transformación turística. Y, para ello, debe aprovecharse y potenciar el carácter inmanente y situado de la ética.

Precisamente al hilo del derecho de visita propuesto por Kant en La paz perpetua, adquiere sentido la segunda contribución en este monográfico, dedicada al derecho del turismo. Alejandro Mantecón y Raquel Huete proponen un marco de comprensión para problematizar las premisas ideológicas que tratan de elevarlo a «categoría de ley moral». Ante el creciente escrutinio al que este se encuentra sometido el derecho al turismo, especialmente debido a su impulso por organizaciones como la OMT (Gascón, 2019), los autores llevan a cabo un estudio de los discursos de organizaciones que desempeñan un papel clave en el turismo y establecen un marco analítico conformado por tres bloques ideológicos - liberal, socialdemócrata y ecosocialista- que ofrece la posibilidad de sistematizar los argumentos que legitiman o cuestionan la consideración del turismo como un derecho.

Las dos siguientes aportaciones abordan las consecuencias del impulso del turismo, las dificultades para regularlo y la dimensión ética que subyace a su crítica en dos ámbitos distintos como son el turismo de ciudad y el turismo comunitario.

El trabajo de Antón Álvarez-Sousa se sitúa en el análisis de los procesos de deslegitimación del turismo, recientemente debatidos en torno al concepto overtourism (Milano, Cheer y Novelli, 2019), en la ciudad de Barcelona. A través de la combinación de metodologías cualitativas y cuantitativas, a partir de la voz de los mismos afectados y del análisis de artículos de prensa, puede comprobarse el extenso abanico de problemas que aparecen cuando una actividad tan heterogénea como el turismo se practica en el mismo espacio en el que la propia ciudadanía lleva a cabo sus actividades cotidianas de trabajo, ocio y descanso. El contraste entre la defensa del empresario local y el rechazo al gran empresariado aliado con el poder financiero y público, que manifiesta la necesidad de forjar una confianza institucional, o la preocupación socioeconómica y cultural, referida a una suerte de identidad de los barrios, constituyen algunos de los problemas del turismo en la ciudad. En este sentido, más allá de la complejidad de un ámbito como el turístico, con distintos actores e intereses que compiten entre sí, el trabajo presentado subraya las expectativas de la ciu- 
dadanía que subyacen a diagnósticos tan variados: que el turismo se desarrolle de una manera responsable y que las instituciones públicas tomen partido en ello.

En efecto, la falta de legitimación del turismo no es nueva. De hecho, como respuesta a esta han ido generándose una cantidad ingente de formas de turismo alternativo con el fin de superar las contradicciones de su desarrollo y continuar así con su orientación al crecimiento (Lovelock y Lovelock, 2013). Entre ellas, el turismo comunitario ha ido presentándose como una modalidad supuestamente orientada a un desarrollo menos problemático. Sin embargo, tal y como muestran Marcos Alonso y Elizabeth de la Cruz, este tampoco escapa de las lógicas productivistas y de los problemas que, como toda interacción, provoca el turismo. Los autores llevan a cabo un escrutinio del turismo comunitario desde una perspectiva específica y escasamente explorada como es la de las éticas indígenas. Mediante este punto de vista ponen de relieve que, en efecto, las virtudes de esta modalidad se sostienen en la participación de pequeñas empresas o autónomos y en la valorización de la cultura. Pero cuando se pasa de los discursos institucionales que tratan de promoverlo a la práctica, las dificultades existentes para conciliar las pretensiones económicas, culturales y comunitarias se vuelven más que patentes. Esta circunstancia se produce sobre todo cuando las iniciativas no surgen de las comunidades, los beneficios finales son escasos, la dependencia a fuentes externas de vida coloca a las comunidades en una situación de dependencia y las representaciones culturales se adaptan a los criterios comerciales, llegando a perpetuar una suerte de «autenticidad escenificada» por parte de quienes viven en destinos con el fin de volverlos atractivos (MacCannell, 1992). Sin necesidad de tener que recurrir a una suerte de esencialismo en relación con la comunidad, los autores subrayan la necesidad de entender que el turismo contiene el potencial de socavar las bases y alterar el dinamismo en el que se conforma una condición de posibilidad para la vida: la comunidad.

Si los cuatro capítulos anteriores ponen el acento principalmente en los niveles institucionales y sociales del turismo, los dos últimos del monográfico abordan las implicaciones de la aceleración en el ámbito de la experiencia.

Almudena Manibardo, Antonio Fernández y Gaia Peruzzi desarrollan un análisis crítico del turismo como parte de la industria cultural. En el contraste entre el actual turista hiperconectado y las nociones románticas del viajero insertas en los imaginarios turísticos existe todo un espacio de reflexión al que, naturalmente, subyacen valoraciones normativas. La crítica del turismo no puede deslindarse del impacto de la tecnología digital en nuestras vidas. La 
apropiación y objetivación de las experiencias de viaje en forma de imágenes se ha vuelto habitual. Del mismo modo que los relatos de los viajes, ya no esperan hoy a su vuelta. Son puestos en circulación generando expectativas que también configuran el turismo. Y, en este sentido, hay que reconocer que el smartphone ha cambiado radicalmente la experiencia del viaje. El presupuesto antropológico de que el encuentro con el otro constituye una condición para la apertura cognitiva se encuentra en entredicho debido a la velocidad de las relaciones y de las tecnologías digitales. A primera vista, esta apertura no tiene límites. Los episodios y las experiencias íntimas ahora están en el dominio de lo universal una vez publicadas. Pero, al mismo tiempo, la curiosidad hacia lo desconocido ha dado paso al control y la previsibilidad que tratan de pautar los algoritmos. Ante estas circunstancias, la recuperación de la experiencia sensorial del viaje como una forma de reconocimiento de la alteridad constituye, para los autores, uno de los posibles marcos de la crítica turística.

Finalmente, Alicia de Mingo desarrolla un trabajo con una visión analítica humanística y ética del turismo alejada de su dimensión mercadotécnica. Indudablemente, el turismo de masas constituye una de las expresiones de la aceleración contemporánea. Sin embargo, la autora también reivindica la necesidad de comprenderlo desde el punto de vista de la demanda de desaceleración simbólica que subyace a su práctica. Más allá de los paradigmas de la autenticidad, pero desde el marco de comprensión tradicional de los estudios turísticos basado en el binario vida ordinaria/extraordinaria (Mccabe, 2002), aspectos como la posibilidad de restauración personal, la búsqueda de lo real o de lo pasado, del encuentro con el otro o de la diferencia, constituyen dimensiones experienciales orientadas a compensar la aceleración y la escasez de exotismo de la vida cotidiana, clave para comprender el sentido del turismo.

En suma, en estos momentos en los que todo el planeta utilizado por y para el turismo parece encontrarse en una situación sin precedentes, no existe mejor ocasión para renegociar las futuras realidades (Fennell, 2020). Las debilidades de los mecanismos de regulación y coordinación globales del turismo, con impactos desde las ciudades hasta las zonas todavía poco turistificadas, la disrupción de nuevas tecnologías que afectan tanto a la coordinación global como a la experiencia turística, probablemente se vean igualmente sujetas a los procesos de aceleración y a las demandas de desaceleración que caracterizan el turismo.

No obstante, las expectativas actuales señalan como deseable que el turismo se desarrolle de manera justa. Naturalmente, es tarea de los actores turísticos trabajar en esa dirección. Pero, como parte de la sociedad, la disciplina de 
la ética del turismo también debe jugar su papel. Para ello podemos tomar dos caminos relacionados: continuar tratando de comprender mejor las dinámicas existentes, debatir qué marcos pueden fundamentar esa crítica y reflexionar sobre las posibles bases éticas para su orientación (López-González, 2018b) y establecer puentes entre la teoría y la praxis turística en un campo que es aplicado por naturaleza (Fennell, 2021).

\section{BIBLIOGRAFÍA}

Caton, Kellee (2012). Taking the moral turn in tourism studies. Annals of Tourism Research, 39 (4), 1906-1928. doi: 10.1016/j.annals.2012.05.021. Clancy, Michael (2018). The rise of slow in a fast world. En Clancy, Michael (Ed.). Slow Tourism, Food and Cities. Pace and the Search for the «Good Life» (1-12). New York: Routledge.

Conill-Sancho, Jesús (2019). ¿Puede ser ecológico el estilo moderno de vida? Pensamiento, 75(283), 171-188. doi: 10.14422/pen.v75.i283.y2019.008.

Cortina, Adela (2003). El quehacer público de las éticas aplicadas: ética cívica transnacional. En Cortina, Adela, García-Marzá, Domingo y Conill, Jesús (Eds.). Razón pública y éticas aplicadas: los caminos de la razón práctica en una sociedad pluralista (13-44). Madrid: Tecnos.

Fennell, David A. (1999). Ecotourism: an introduccion. London: Routledge. Fennell, David A. (2018). Tourism ethics. 2. ${ }^{\text {a }}$ ed. Clevedon: Channel View. Fennell, David A. (2019). The Future of Ethics in Tourism. En FayosSolà, Eduardo y Cooper, Chris (Eds.). The future of tourism. Innovation and Sustainability (155-177). Cham (Switzerland): Springer. doi: 10.1007/978-3-319-89941-1.

Fennell, David A. (2020). Technology and the sustainable tourist in the new age of disruption. Journal of Sustainable Tourism, 29(4), 1-7. doi: 10.1080/o9669582.2020.1769639.

Fennell, David A. (2021). The tourism knowledge translation framework: bridging the canyon between theory and practice. Current Issues in Tourism, 1-18. doi: 10.1080/13683500.2021.1887099. Fullagar, Simonem, Markwell, Kevin y Wilson, Erika (Eds.) (2012). Slow 
Tourism: Experiences and Mobilities. Bristol: Channel View.

García-Marzá, Domingo (2003). La responsabilidad por la praxis: la ética discursiva como ética aplicada. En Cortina, Adela, García-Marzá, Domingo y Conil, Jesús (Eds.) Razón pública y éticas aplicadas: los caminos de la razón práctica en una sociedad pluralista (159-190). Madrid: Tecnos.

Gascón, Jordi (2019). Tourism as a right: a «frivolous claim» against degrowth? Journal of Sustainable Tourism, 27(12), 1825-1838. doi: 10.1080/og669582.2019.1666858.

Gössling, Stefan, Scott, Daniel y Hall, C. Michael (2020). Pandemics, tourism and global change: a rapid assessment of COVID-19. Journal of Sustainable Tourism, 29(1), 1-20. doi: 10.1080/09669582.2020.1758708.

Harvey, David (1989). The Condition of Postmodernity: An Inquiry into the Origins of Cultural Change. Oxford: Blackwell.

López-González, José L. (2018a). Del código ético a la convención internacional. Un panorama crítico de la organización mundial del turismo desde la perspectiva del cosmopolitismo. Oxímora. Revista internacional de Ética y Política, 12, 205-223. doi: 10.1344/oxi.2018.

López-González, José L. (2018b). Exploring discourse ethics for tourism transformation. Tourism, 66(3), 269-281.

López-González, José L. (2019). El neuroturismo en la era de la aceleración social: una aproximación a sus implicaciones éticas. En Cañada, Ernest y Murray, Iván (Eds.). Turistificación global: perspectivas críticas en turismo (145-160). Barcelona: Icaria.

López-González, José L. y Medina-Vicent, María (2020). Las Kellys y el turismo: de la invisibilidad del cuidado a la visibilidad política. Digithum, 2020(25), 1-13. doi: 10.7238/d.voi25.3175.

Lovelock, Brent y Lovelock, Kirsten M. (2013). The ethics of tourism: critical and applied perspectives. New York: Routledge.

MacCannell, Dean (1992). Empty meeting grounds. London: Routledge.

Mccabe, Scott (2002). The Tourist Experience and Everyday Life. En Dann, Graham M.S. The Tourist As a Metaphor of the Social World (61- 
75). New York: CABI.

Milano, Claudio, Cheer, Joseph M. y Novelli, Marina (Eds.) (2019). Overtourism: Excesses, Discontents and Measures in Travel and Tourism. Wallingford, Oxfordshire / Boston, MA: CABI. doi: 10.1108/jtf-o92019-088.

Rosa, Hartmut (2005). Beschleunigung: Die Veränderung de Zeitstrukturen in der Moderne. Frankfurt am Main: Suhrkamp Verlag.

Tribe, John (2009). Philosophical Issues in Tourism. En Tribe, John (Ed.). Philosophical Issues in Tourism (3-22). Bristol: Channel View. 